uses to test various ideas about scientific communities, natural philosophy and scientific change.

Cantor takes a sociological approach. This is most fruitful in the treatment of the surprisingly large number of fluid theorists that he has uncovered, for they were for the most part attempting to use theories of light in Biblical interpretation and were not engaged in science, by making predictions, doing experiments or explicating optical phenomena. By Cantor's own account, they were marginal to the British scientific community at the beginning of his period of study and irrelevant by its end.

When Cantor turns to more serious scientific theories, such as the Newtonian emission theory, his sociological concepts are too narrowly conceived. For instance, he argues that no research occurred in the emission theory from 1700 to 1740 , because its proponents were diverted by teaching. Besides the simple confusion of a cause and a correlation, this sort of claim could readily be tested by a comparison with the situation on the Continent during that period. Indeed, Cantor's self-imposed restriction to Britain and Ireland is a serious flaw, for a strong case can be made that the British Isles were a scientific backwater for most of the period from 1704 to 1840 , so that what he has given us is actually an account of a relatively stagnant scientific community, rather than a progressive one. Thus, at the beginning of the nineteenth century, when he declares the emission theory to have been in decay in England, it was flourishing in France in the hands of Laplace, Biot and Malus.

An explanation for the initial neglect of Young's contributions - the most important and original British work in this study - provides, as Cantor recognizes, a critical test of his account. I am, however, only partly persuaded by his solution, namely, that the principle of interference was rejected because it was associated with Young's unoriginal wave theory. Cantor underestimates the quality of Young's work and depends too much on denigrating both him - Euler's "English disciple of moderate competence" - and his work, which he does not fully and clearly explain. $\mathrm{He}$ also introduces an artificial distinction that too sharply differentiates Young's and all earlier "vibration" theories from Fresnel's mathematical "wave" theory, whereas I believe there is a genuine continuity from Huygens through Euler and Young to Fresnel.

The most valuable feature of Optics after Newton is the vast quantity of primary literature described by Cantor, which can serve as a base for future work on the history of optics, not just British theories of light.

Alan E. Shapiro is Associate Professor of History of Science and Technology at the University of Minnesota. He is the editor of The Optical Papers of Isaac Newton; the first volume, The Optical Lectures 1670-1672, was recently published by Cambridge University Press.

\section{Firsts for feminism}

\section{Morris Kline}

\section{A Convergence of Lives: Sofia}

Kovalevskaia, Scientist, Writer, Revolutionary.

By Ann Hibner Koblitz.

Birkhäuser: 1984. Pp.305. \$19.95.

WHY should anyone be interested in a biography of someone whose name, much less her work, is known to very few people and who died nearly one hundred years ago? The chief reason for this fine biography is that Sofia Kovalevskaia was a first-class mathematician, who achieved a place for herself in a period when women were hardly recognized outside the home.

In her time, Kovalevskaia achieved high professional status; she was the first woman to be awarded a doctorate in mathematics, the first (outside Italy) to become a professor of mathematics, and the first to serve as editor of a major mathematical journal. She also made impressive contributions to literature, and engaged in social and political efforts in the cause of women's rights. All of these activities were carried on during a life span of only 41 years (1850-1891) and despite the inevitable opposition from male professors in mathematics and other fields.

Kovalevskaia had become attracted to mathematics even as a child, when she was instructed by tutors. To counter the opposition to women as students in the higher Russian academic institutions, she managed by a rather frequently used subterfuge, called fictitious marriage legal but not sexual - to get out of the country in order to study mathematics. Most of the book is devoted to her development, to the lives of her immediate family and friends, and to her troublesome relations with her husband, who was a geologist. Later, she and her "fictitious" husband did become sexually involved; the marriage produced a daughter.

Kovalevskaia's pursuit of mathematics was her main drive in life. After leaving Russia, she became a student at the University of Heidelberg where she spent several years. There she learned of the work of Karl Theodore Weierstrass (1815-1897), one of the leading mathematicians of Europe and a professor at the University of Berlin. Though she was denied admission to the university, Weierstrass was greatly impressed with her ability and took her on as a private student. With his backing she received a doctorate in mathematics.

Fortunately, Gösta Mittag-Leffler, a liberal Swedish mathematician, then sponsored her for a professorship at the University of Stockholm, a post she took on leaving Berlin and held for many years. During these years, and even earlier, she came to know the leading mathematicians of Europe; it was through recognition in this way, and despite considerable opposition from the establishment, that she was elected to the Russian Imperial Academy of Sciences.

To those who are primarily concerned with the history of mathematics as such, this book will be a little disappointing. There is little mention of Kovalevskaia's actual work, beyond a list of her publications. But it is clear that whereas some mathematicians make brilliant creations as youths, Kovalevskaia developed slowly. In her case the educational difficulties she faced were at least partly responsible, and had she lived longer she would have surely produced much more. Equally interesting to historians of the intellectual connections in the nineteenth century are many of the remarks and details concerning the mathematicians with whom Kovalevskaia kept contact. In particular, her relationship with Weierstrass, who practically adopted her as a daughter, reveals much of that man's noble character.

Ann Hibner Koblitz quite clearly has done a great deal of research in Russia and Stockholm to write this lucid biography. The bibliography is immense and will be of great value to other scholars. Her book should also be of interest to a broad audience, as an example of what a woman could accomplish in nineteenth-century anti-feminist Russia and for the insight into the political and social climate of that period. My only quibble is the word "revolutionary" in the title. Kovalevskaia was indeed what we nowadays know as a feminist. But she was not a militant.

Morris Kline is Professor Emeritus at the Courant Institute of Mathematical Sciences, New York University. He is author of Mathematical Thought from Ancient to Modern Times (Oxford University Press, 1972).

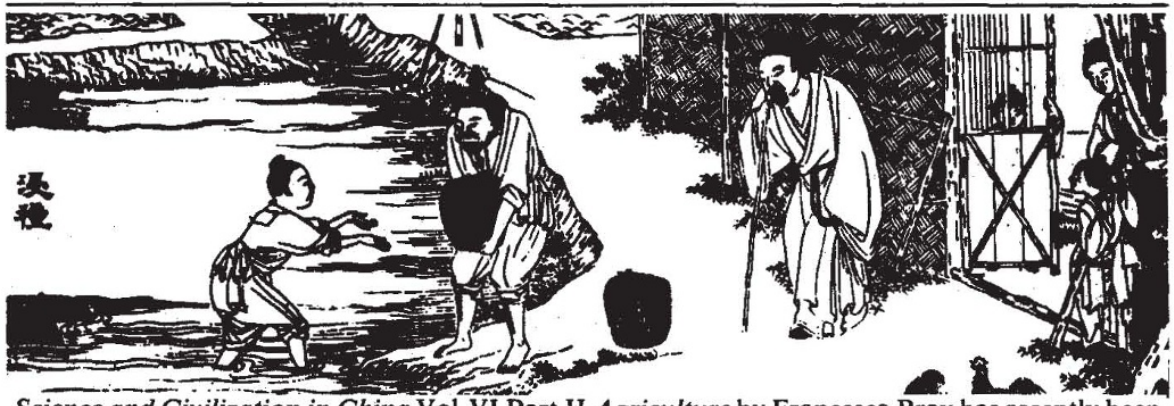

Science and Civilization in China Vol.VI Part II Agriculture by Francesca Bray has recently been published by Cambridge University Press and will be reviewed in a forthcoming issue of Nature. 